\title{
Recovery from decrement as a function of successive alternations of work and rest periods
}

\author{
Edward A. Bilodeau \\ TULANE UNIVERSITY
}

\begin{abstract}
The classical curve of recovery as a function of rest duration is increasing and negatively accelerated. The present study finds that this summary characterizes Rest 1 and cannot be generalized to Rest $n$ successfully. The qualification is necessary for both work and learning tasks.
\end{abstract}

\section{Problem}

Decrement and recovery from decrement have been extensively investigated in the learning of motor skill. The data associated with interpolating a single restbetween two practice periods have received considerable attention because their study bears directly upon the growth and decay of such response-depressing variables as $\mathrm{I}_{\mathrm{R}}$ and $\mathrm{S}_{\mathrm{S}} \mathrm{I}_{\mathrm{R}}$ (Bilodeau \& Bilodeau, 1961).

Spontaneous recovery as an increasing, negatively accelerated function of rest duration has been reported any number of times, and has surely attained a classical status (Kimble \& Horenstein, 1948). It is quite important to realize, however, that the observed relationship pertains to the recovery data of the first period of rest. Recovery should vary with duration of the rest period, the ordinal rest number, and their interaction. This study presents evidence on all three relationships instead of the usual one.

Using a work task (cranking), Bilodeau (1954) compared recovery magnitudes for two rest durations over 19 rests. The massed group cranked for twenty $30-\mathrm{sec}$. periods with nineteen interpolated rests of $10 \mathrm{sec}$. each; the spaced group practiced with a work-rest cycle of 30-180 sec. Four important successive recovery phenomena were described: the amount recovered for (1) the spaced group decreases progressively, (2) the massed group increases at first and then decreases, (3) an intermediate spacing might be expected to show no trend, and (4) the massed and spaced group can be of equal magnitude. The present study is a repetition of the cranking experiment, except that a task for which there is a strong learning component was used in order to test whether the four cranking phenomena were unique to a work task.

\section{Method}

A total of 192 naive airmen at Lackland AFB was used in three groups of 64 . The apparatus was four units of the Two-Hand Coordination Test. The task was to learn to track a .5 in moving target by means of two control cranks (Melton, 1947). Two full turns of the control effected a complete traversal of the target by the follower. The target ran continuously when desired, and $\mathrm{E}$ was able to program any one of four orders of slightly different target courses. For any one S, the same target courses preceded and followed every rest period.

The instructions emphasized the importance of tracking as accurately as possible. The treatments of work and rest were more extreme than ordinarily used in distribution studies and were administered to four Ss at a time. The three groups were different only in terms of the duration of rest interpolated between 15 successive 4-min. trials. The 14 rest periods were either $1 / 4,1$, or $8 \mathrm{~min}$. long, and the sessions per group lasted 63.5 , 74 , or 172 min., respectively.

\section{Results}

The TOT scores are plotted in Fig. 1 with the breaks in the curves representing the rest periods. Over the hour of practice, TOT moved from 20 to $80 \%$ with the increment in performance directly related to the duration of the rest. Generally, there is a decrement within work periods because of inhibition; there is an increment between work periods because of recovery from inhibition.

Were the recovery data for Rest 1 plotted as a function of rest duration, they would be consistent with previous findings on the rotary pursuit apparatus and other learning tasks, i. e. recovery is an increasing, negatively accelerated function of rest duration. Beyond Rest 1 , however, the function changes in form and quantity and the classical curve no longer obtains. This is best brought out in Fig. 2 where rest duration is the

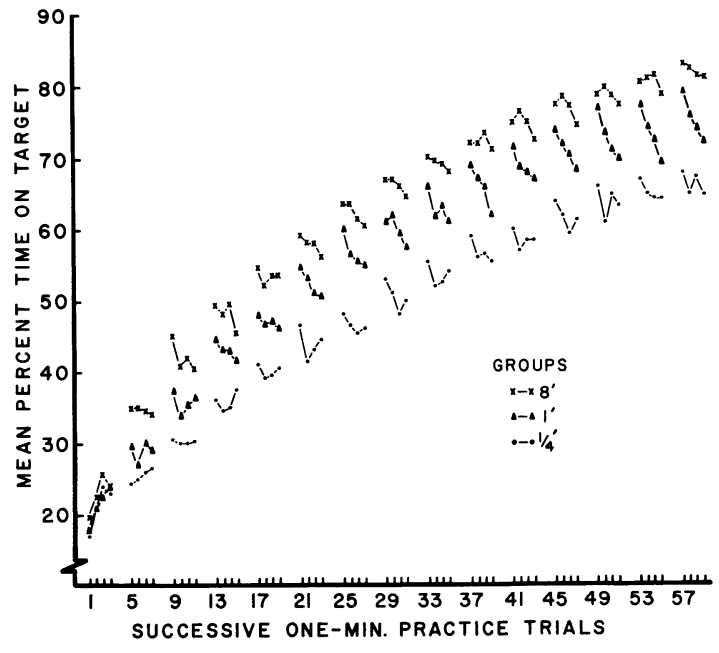

Fig. 1. Performance curves for $60 \mathrm{~min}$. of practice within which 14 rests of 8,1 , or $1 / 4 \mathrm{~min}$. duration have been interpolated. 


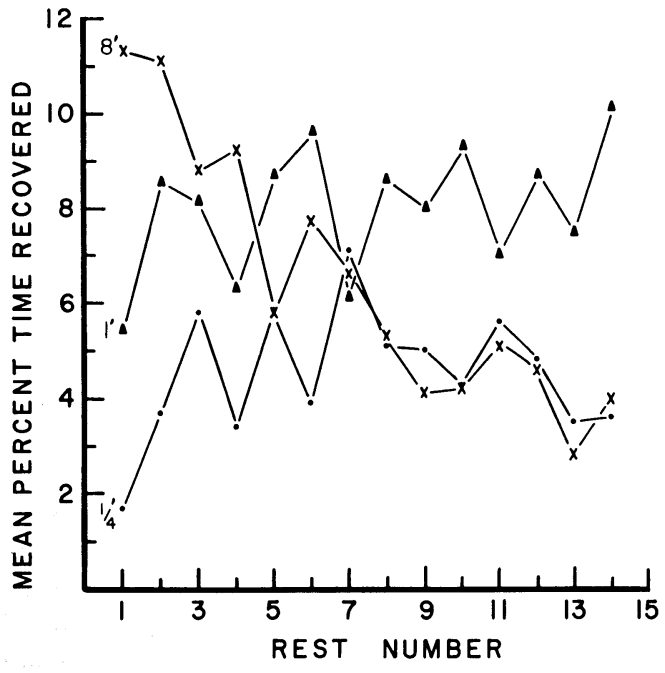

Fig. 2. Successive recovery functions with rest number as the independent variable and duration of rest as the parameter.

parameter and ordinal rest number is the independent variable.

The curves of Fig. 2 converge on a common value at Rest 7, and an F less than unity at Rest 7 bears this out. After Rest 7, the recoveries of the most massed (1/4') and the most spaced ( $\left.8^{\prime}\right)$ groups decline, and appear no different in magnitude. The intermediate rest group is considerably and unaccountably variable and shows no marked trend. An F of 10.29 at Rest 14 is significant beyond the .01 level with $2 / 189 \mathrm{df}$ and is attributed to Group 1'.

\section{Abstract}

BRAINE, M. D. S., \& SHANKS, BETTY L. (Walter Reed Army Institute of Research). The development of conservation of size. J. verb. Learn.verb. Behav., in press.-Using several illusions, a stimulus was first made to look bigger and then to look smaller than another stimulus, on successive trials. 4 experiments required correct differential responses to the questions "Which looks bigger?"' and "Which is really bigger?", and one experiment required that the question "Which is bigger?" be interpreted as a question about real size.

\section{Discussion}

Except for the failure of the recovery scores of Group 1 ' to turn downward after several rest periods, the magnitudes and trends in Fig. 2 are in substantial agreement with the four phenomena previouslyobtained on the crank or work task. The interpretation of the work phenomena borrowed freely from $\mathrm{I}_{\mathrm{R}}$ theory developed in learning contexts (Bilodeau, 1954). Hence, it should suffice for the present learning task as well.

Ten years have passed since the writer first noted that the classical form of recovery with rest duration was limited to Rest 1 and ought not to be generalized to Rest $\mathrm{n}$. The present findings of decreasing and equal recovery between Groups 1/4' and $8^{\prime}$ again pose serious problems for students of Rest 1 . Research on distribution of practice in this decade has grown out of popularity; hopefully, not because it is thought to be well understood. The terminal results of Groups 1/4' and 8 ' suggest the future usefulness of such ideas as little $I_{R}$ (or fatigue) and possible equality or near equality in $I_{R}$.

\section{References}

BILODEAU, E. A. Rate recovery in a repetitive motor task as a function of successive rest periods. J. exp. Psychol., 1954, 48, 197-203.

BILODEAU, E. A., \& BILODEAU, I. McD. Motor-skills learning. Annu. Rev. Psychol., 1961, 12, 243-280. KIMBLE, G. A. \& HORENSTEIN, B. R. Reminiscence as a function of the length of interpolated rest. J. $\exp$. Psychol., 1948, 38, 239-244.

MELTON, A. W. (Ed) Apparatus tests. AAF Aviation Psychology Program Research Report No. 4, 1947.

By age 5 yr. a majority of children are capable of a quite general distinction between real and phenomenal size. The earliest stages of size conservation are not amenable to study with traditional Piagetian procedures because children under 7 do not interpret "bigger"' as "really bigger," unless feedback information forces this interpretation. It is proposed that what has to be explained in accounting for the conservations is the emergence of a general distinction between real and phenomenal properties of objects. (Pre-publication copies available from the authors.) 